\title{
CONTRIBUIÇÕES E IMPLICAÇÕES DA PERSPECTIVA DIALÓGICA: 0 SELF DO(A) TERAPEUTA NA TERAPIA FAMILIAR/CASAL
}

\section{ANITA DA COSTA PEREIRA MACHADO \\ Instituto Noos, São Paulo/SP, Brasil Instituto Fazendo História, São Paulo/SP, Brasil}

lguns artigos da edição de abril de 2019 da revista Nova Perspectiva Sistêmica chamaram minha atenção, convidando-me à reflexão. Houve um com que me conectei mais fortemente por abordar um aspecto central nas terapias de família e casal, introduzido pela cibernética de segunda ordem, que se refere ao reconhecimento do terapeuta também como construtor da realidade sobre a qual se propõe, em alguma medida, intervir. "Contribuições e implicações da perspectiva dialógica: o self do(a) terapeuta na terapia familiar/casal" é um artigo que oferece uma reflexão acerca dos efeitos da perspectiva dialógica na construção do "ser terapeuta" de família/casal por meio de uma revisão bibliográfica qualitativa. O método desse trabalho, portanto, já me parece indicar uma conexão com a perspectiva dialógica, pois se refere a uma revisão narrativa de cunho exploratório, o que sugere, a meu ver, um modo de revisão que implica uma "conversa" entre o material pesquisado e aquele que pesquisa.

No artigo os autores situam a reflexão sobre self do terapeuta a partir do pensamento pós-moderno, que de fato possibilita este giro epistemológico, em que a ideia de neutralidade e objetividade, tão cara à modernidade e à pesquisa científica tradicional, é problematizada e rejeitada como modelo absoluto de produzir ciência. Conceber as implicações da subjetividade do terapeuta e tomá-la como ferramenta dos processos de mudança no contexto terapêutico é algo que, entendo, exige uma produção de conhecimento cuidadosa. Neste sentido, um dos aspectos do artigo que me tocou e evidencia que essa produção deve estar atenta refere-se à noção de autorreferência, expressa na afirmação: "Quando se torna concebível colocar a objetividade e a neutralidade do(a) terapeuta entre parênteses, torna-se mais relevante o entendimento sobre como pode repercutir nossa autorreferência nos sistemas que integramos". (Cabral e Sales, p. 22, 2019). Este enunciado me fez pensar acerca das fronteiras entre terapeuta e família e que quando essas são intencionalmente flexibilizadas há questões éticas importantes a serem consideradas. Por exemplo, em relação à autorreferência, que em si não é boa ou ruim, mas me parece importante, do ponto de vista ético, estar acompanhada da reflexão: a serviço de quem tal autorreferência é inserida no campo terapêutico? Da família, da relação terapêutica ou de satisfações de necessidades particulares do terapeuta? Parece-me que esta indagação pode produzir como efeito uma atitude de crítica e de interrogação permanente sobre as afetações do profissional. Uma postura necessária que dialoga com o que Gergen (1987) identificou como dois traços presentes na ética das relações, que são a consciência e autorreflexividade, fundamentais para um uso crítico da autorreferência. 
Prosseguindo no artigo, um aspecto que chamou minha atenção, ao expor a busca por publicações que contenham os termos "terapia familiar" combinadas com "perspectiva dialógica, dialogismo e self dialógico", foi a ausência de pesquisas nacionais que utilizam o conceito de self dialógico na terapia familiar, e que me levou a indagar o porquê desta ausência. Recordando a minha trajetória acadêmica, tanto da graduação quanto da pós-graduação, o que aprendi sobre terapia familiar não incluiu o construcionismo social ou o dialogismo. E embora faça mais de 17 anos que tenha me formado, tenho notícias de cursos de Psicologia em que, na disciplina de Terapia Familiar, as contribuições das abordagens pós-modernas não estão presentes. Isso me faz supor que a ausência de pesquisas acadêmicas sobre a perspectiva dialógica ocorre por não estar inserida ou estar de modo incipiente dentro da academia. Já em relação à literatura científica internacional, Cabral e Sales localizam os estudos de Peter Rober como pesquisador principal ou em coautoria com Jaakko Seikkula e Aarno Laitila, destacando-se na produção científica de métodos dialógicos na investigação de processos de mudança na terapia familiar. O que me fez reafirmar minha percepção anterior, ao menos de Peter Rober e Jaakko Seikkula, como ativos pesquisadores envolvidos não só em produzir novas práticas, mas também em pesquisas e conhecimento científico das abordagens dialógicas no campo da terapia familiar/casal.

Em seguida, o texto apresenta uma interessante análise dos autores estrangeiros que mais aproximam o conceito de self dialógico com terapia familiar/ casal, por meio de um recorte de conceitos ligados à abordagem dialógica, dividindo o texto em cinco partes. São elas: Diálogo e espaço dialógico; O self dialógico; Posicionamento e conversação interna do(a) terapeuta; Reflexões sobre o conceito de não saber e Pesquisa como aliada da prática. Reconheço que, ao ter contato com esta sistematização, que contempla cinco conceitos, fiquei indagando como se construiu o mencionado recorte. Imaginando que houve a leitura de publicações dos autores mencionados no artigo, perguntei-me: como ocorreu o processo de escolha dos conceitos? Embora o artigo faça menção a terem sido "as concepções mais salientadas", ainda assim fiquei com a interrogação do como se deu a captura do que ficou saliente para os autores.

Acompanhando a sistematização proposta, me detive no primeiro tópico por apresentar o diálogo a partir da perspectiva bakhtiniana, o que enriqueceu meu olhar sobre o assunto ao avançar na compreensão de diálogo para além de uma experiência de troca, aceitação e entendimento do ponto de vista do interlocutor. Percebi que, mesmo que há muito tempo trabalhe com a lógica do diálogo, tendo como principal fonte de inspiração Paulo Freire, a perspectiva dialógica, apresentada no artigo, me permitiu avançar na compreensão. O deslocamento da ideia de diálogo como oposto a monólogo, como evidenciam Cabral e Sales, “...uma dinâmica tensa entre as dimensões monológicas e dialógicas existentes em uma conversação” (p. 25, 2019), fez-me lembrar os trabalhos que realizei no campo social. Projetos sociais que trabalhavam com a perspectiva da cultura de paz não como ausência de conflito e sim uma construção relacional que o inclui (Balestreri, 2003). Pensando em trabalhos, seja como terapeuta seja como educadora, em que tenho como papel facilitar experiências de conversação, reconheço o ganho significativo, na minha atuação, de retirar o diálogo de um entendimento idealizado, mantendo-o 
conectado com as tensões envolvidas em uma conversação, o que se traduz em reconhecer, como exposto no artigo, o diálogo permeado por aspectos de composição e construção, bem como de dispersão e desconstrução.

$\mathrm{O}$ cuidado com os significados que passam a ser partilhados entre terapeuta e família, também abordado nessa parte do texto, me conectou com minha preocupação relativa à ênfase na empatia com o cliente. Embora, por um lado, a empatia seja ponto de partida para o trabalho se constituir por outro para ser terapêutico, a diferença também precisa ser garantida. Encontrar no texto tal compreensão contribuiu para minha prática na medida em que reafirma o cuidado com a identificação excessiva do terapeuta. Favoreceu a lembrança da direção do trabalho terapêutico voltado para mudança, ou seja, além de uma experiência empática, a terapia é também um processo de incluir a diferença de modo a permitir novas descrições associadas a uma experiência afirmativa da família como produtora de proteção e crescimento para seus membros.

O conceito de não saber vinculado ao self do terapeuta foi outro tópico apresentado no artigo que gerou reflexões. Nesse ponto da leitura passei a recordar o incômodo sentido no primeiro contato com esse conceito. Por um lado, reconheço a centralidade do não saber para pensar a constituição do self do terapeuta dialógico, pois possibilita um deslocamento do seu lugar de poder como o expert sobre o sofrimento do outro. No entanto, esse "não saber" me soava como um ausentar-se de pensar sobre qual seu poder no lugar de não saber. Pensava, a partir de Foucault (1988), que o poder está em toda parte e é intrínseco às relações humanas; neste sentido, achava perigosa uma afirmação sugerindo uma compreensão que subtrai um poder inerente ao papel social do terapeuta como detentor de um saber sobre o outro. E por mais que esse pressuposto precise ser problematizado, penso que a indagação de qual o poder do terapeuta no contexto de desconstrução do lugar de suposto saber poderia facilitar o rompimento com a lógica dicotômica do que sabe e do que não sabe. Apreciei, portanto, o artigo apresentar uma reflexão crítica. É como se conversassem com meus questionamentos e inquietações acerca de tal conceito. As contribuições da posição de não saber não são poucas e são explicitadas no texto. Valorizar, por exemplo, o conhecimento dos membros da família sobre eles próprios e poder com eles aprender. Neste lugar de aprendiz o terapeuta é convidado a refinar sua experiência de diálogo com a família, uma vez que, como ensina Rober, evita conversas internas monológicas, conecta-se com a complexidade, com a incerteza e com as múltiplas vozes que fazem parte da sua conversação interna. Interessante neste ponto como o nexo entre o não saber e o aprender é estabelecido fortemente, ou seja, é por meio do não saber que o terapeuta é mais capaz de aprender sobre a verdade narrativa do cliente. Ao mesmo tempo, fez muito sentido a discussão do artigo sobre os riscos de uma posição passiva a partir de um lugar de não saber, assim como os dois argumentos que sustentam a problematização. O primeiro refere-se à importância do self experienciador do terapeuta, que também produz um saber sensível no encontro com a família/casal e que pode ser aproveitado no diálogo com o self profissional do terapeuta. Refleti que essa ideia da experiência é forte para mim, relaciona-se com a noção de algo especial vivido, marcante pela força não só no âmbito da cognição, mas que também envolve o corpóreo, um campo de sensações e afetos. Recordo a força que ganham as sessões quando acesso essa dimensão da experiência junto com o(s) cliente(s). Winnicott (1975) é um autor 
que me ajuda nesta compreensão da experiência no aspecto de algo que acontece entre duas pessoas; não é criação exclusiva de um, ou já está lá criado, mas se cria a partir desse encontro, em um espaço potencial, o que vai possibilitando uma qualidade relacional que em si já é terapêutica. Já o segundo argumento se dirige ao reconhecimento do status sociocultural construído do terapeuta como um expert, o que exige, a meu ver, mais do que uma rejeição deste lugar de poder, um exercício terapêutico de trabalhar a construção de um espaço dialógico que inclua as tensões, as dúvidas, o saber e o não saber.

Agradou-me, no último tópico abordado por Cabral e Sales, ao introduzir a ideia de pesquisa como aliada da prática, a explicitação de um pesquisar que acesse a dimensão dialógica da terapia de família/casal. A contribuição deste tópico, para mim, além de reforçar o lugar do terapeuta como aprendiz a partir da perspectiva da pesquisa, foi o modo de investigar os aspectos dialógicos por meio de microanálise de casos clínicos. No acesso do processo de pesquisar não só as vozes explícitas, mas também as vozes internas do terapeuta facilitaram a prática do exercício de uma escuta ampliada em sessão. Deste modo, penso que a riqueza dessa microanálise foi evidenciar a produção de um diálogo entre os diálogos explícitos e implícitos gerados em sessão, possibilitando uma autorreflexividade da própria clínica. Além disso, considero o recurso das filmagens da sessão utilizado para produzir a microanálise como um modo potente de facilitar o acesso de parte do diálogo interno do terapeuta. É uma escolha metodológica que facilita o contato com a dimensão não explícita. No exemplo, trazido pelos autores, extraído de uma pesquisa de Rober, ficaram evidentes os ganhos qualitativos do recurso da filmagem. Entendo que a pesquisa, neste contexto, reafirma a perspectiva dialógica, uma vez que parte de uma postura de não saber e possibilita uma intensificação da experiência do diálogo pelo acesso à conversação interna do terapeuta, funcionando como ferramenta para o desenvolvimento do self dialógico.

Por fim, compreendo que o exercício da escrita deste texto/Ecos conduziu-me a ler e reler o artigo escolhido, o que me fez encontrar mais e mais vozes a cada nova leitura, tanto internas quanto externas. Um exercício dialógico, uma vez que na conversa com o artigo vivenciei o que foi tão bem apresentado de modo teórico pelos autores. Diálogo constituído pela multiplicidade de vozes não necessariamente harmônicas entre si, mas dotadas de possibilidades de gerar novos modos de ver e produzir as relações.

\section{REFERÊNCIAS}

Balestreri, R. (2003). Na inquietude da paz. Porto Alegre: Edições Capec.

Cabral, D. W. A. \& Sales, C. M. D. C. P. (2019). Contribuições e implicações da perspectiva dialógica: o self do(a) terapeuta na terapia familiar/casal. Nova Perspectiva Sistêmica, 63, 21-41.

Foucault, M. (1988). História da sexualidade: a vontade de saber. Rio de Janeiro: Edições Graal.

Gergen, K. J. (1989), La psicologia posmoderna y la retórica de la realidad, en T. Ibañez (coord.), El Conocimiento de la Realidad Social, Barcelona: Sendai, págs. 157-185.

Winnicott , D. W. (1975). O Brincar e a Realidade. Rio de Janeiro: Imago Editora. 
ANITA DA COSTA PEREIRA MACHADO

Graduada em Psicologia pela PUC-PR, Terapeuta Familiar e de Casal pelo Intercef, Mestre em Psicologia Escolar e Desenvolvimento Humano - IPUSP. Terapeuta associada do Instituto Noos, Técnica do Instituto Fazendo História, Psicoterapeuta individual e de família/casal clínica particular.

E-mail: nini.costa@hotmail.com 